\title{
DIELECTRIC RELAXATION OF DIHYDRIC ALCOHOL-1,4-DIOXANE MIXTURES USING TIME DOMAIN TECHNIQUE
}

\author{
M.N. Shinde, R.B. Talware, and A.C. Kumbharkhane \\ School of Physical Sciences, Swami Ramanand Teerth Marathwada University, Nanded - 431 606, Maharashtra, India \\ E-mail: akumbharkhane@yahoo.co.in
}

Received 18 September 2010; revised 4 December 2010; accepted 17 March 2011

\begin{abstract}
Complex dielectric permittivity measurements of 1,2-propanediol-1,4-dioxane mixtures has been carried out at different concentration and in the frequency range of $10 \mathrm{MHz}$ to $20 \mathrm{GHz}$ using time domain reflectometry (TDR). The least squares fit method has been used to obtain the static dielectric constant, relaxation time, and Bruggeman factor for binary mixtures. The Kirkwood-Frohlich theory is applied to compute the dielectric constant for the mixtures. It adequately reproduces the experimental values of static dielectric constants for the 1,2-propanediol-dioxane mixtures. The excess parameters confirm that the heteromolecular hydrogen bonding interactions between 1,2-propanediol and dioxane molecules vary significantly in the mixture. The Bruggeman model for the nonlinear case has been fitted to the experimental dielectric data for mixtures.
\end{abstract}

Keywords: dielectric relaxation, time domain reflectometry, alcohols

PACS: $77.22 . \mathrm{Gm}$

\section{Introduction}

Alcohols are typical hydrogen bonding liquid and are widely used in industry [1-4]. In the last 20 years the liquid structure of several monohydric alcohols such as methanol, ethanol, 1-propanol, 2-propanol has been extensively studied by spectroscopic techniques [5-11]. However, liquid dihydric alcohols are not well studied by spectroscopic techniques. Dihydric alcohols can be classified into four groups according to the position of the hydroxyl groups, which are named to as 1,2-diol, EN-diol, EE-diol, and NN-diol. The hydroxyl groups of 1,2-diol are present on the terminal carbon atom and neighbouring carbon atom. The hydroxyl groups of EN-diol are present on the carbon atom at one terminal and the second carbon atom forms the opposite terminal. The hydroxyl groups of EE-diol are present on the carbon atoms at both terminals. The hydroxyl groups of NN-diol are present on the neighbouring carbon atoms of both terminals. 1,2-propanediol is a dihydric alcohol. The hydroxyl groups are present on the terminal carbon atom and neighbouring carbon atom, therefore the strong intramolecular interaction, possible through hydrogen bonds in 1,2-propanediol, results in peculiar dynamics properties compared with other monohydric alcohols. The excess volume, viscosities, and excess Gibbs energies of activation of binary mixtures were studied to understand solute-solvent inter- action [12-21]. Excess molar volumes and partial molar volumes were determined for dilute aqueous solutions of 1-propranol, 1,2-propanediol, 1,3-propanediol by Romero et al. [22].

The dielectric constant is one of important physicochemical properties of the mixed solvents, which enhance most of the biological, pharmaceutical, chemical, physical, analytical, laboratory industrial application [8]. The dielectric studies of 1,2-propanediol on addition of dioxane provides information about breaking of molecular structure in the systems. Dielectric characterization has great potential in studying the $\mathrm{H}$-bond interactions: dipolar alignments, hydrogen bond connectivity, and stoichiometric ratio of stable adduct formation in mixed solvents [8, 16, 17]. Crossely et al. [23] have examined the dielectric permittivity and loss for a series of diols. It is observed that the relaxation times for the diols are almost independent of alkyl chain length. Hanna et al. [24] have also studied dielectric relaxation of diol mixtures. A correlation between the monohydric alcohols and the diols is obtained from the values of the relaxation time and the number density of molecules. This can be interpreted as an indication that only one hydroxy group in the diol is active in the main relaxation process. This implies that the other end of the diol molecule remains "anchored" to another molecule by the hydrogen bond. This reduces the flexibility at 


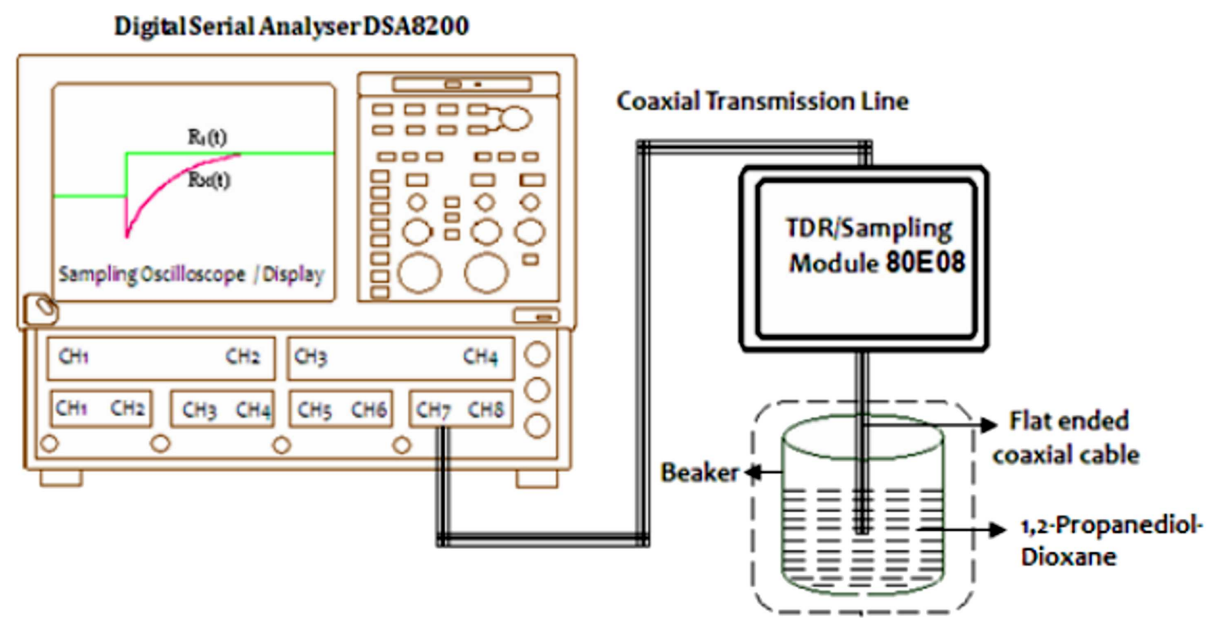

Fig. 1. Block diagram of time domain reflectometry (TDR).

the molecular level leading to a slower relaxation than in normal alcohol. Main purpose of this study is to understand the dielectric behaviour of 1,2-propanediol in terms of hydrogen bond and modification of hydrogen bonding due to presence of other non-polar molecules. In the present work dielectric measurements of the mixtures of 1,2-propanediol-dioxane using TDR method are reported. The complex dielectric permittivity in the frequency range of $10 \mathrm{MHz}$ to $20 \mathrm{GHz}$ has been determined. The static dielectric constant, relaxation time, Bruggeman factor, Kirkwood correlation factors, excess dielectric permittivity, excess inverse relaxation time have been determined for 1,2-propanediol-1,4-dioxane mixtures at $25^{\circ} \mathrm{C}$.

\section{Experiment}

1,2-propanediol and 1,4-dioxane were purchased from Aldrich Chemicals Ltd. and used without further purification. The solutions were prepared at different volume fractions of alcohol in dioxane. The complex dielectric permittivity of the solutions was determined in the frequency range of $10 \mathrm{MHz}$ to $20 \mathrm{GHz}$ at $25^{\circ} \mathrm{C}$ using time domain reflectometry method [25]. The apparatus used in this work is shown in Fig. 1. The Tektronix DSA8200 sampling oscilloscope with $30 \mathrm{GHz}$ bandwidth and TDR module 80E08 with step generator unit was used. A fast rising step pulse with $18 \mathrm{ps}$ incident pulse and $20 \mathrm{ps}$ reflected pulse time was propagated through coaxial lines. All measurement is carried out in open load condition. The reflected pulses with and without sample were digitized with 2000 sampling points in the time window of $5 \mathrm{~ns}$. The Fourier transformation of the pulses and data analysis was done earlier to determine the complex permittivity spectra in the



Fig. 2. Complex permittivity with frequency $(\mathrm{GHz})$ at $25^{\circ} \mathrm{C}$.

frequency range of $10 \mathrm{MHz}$ to $20 \mathrm{GHz}$ [25]. Figure 2 gives one example of the frequency dependent complex permittivity spectra for 1,2 -propanediol at $25^{\circ} \mathrm{C}$.

\section{Results and discussion}

In general, the dielectric loss spectrum of the alcohol is an asymmetric shape, and it is described by the Havriliak-Negami equation. The complex permittivity $\varepsilon^{*}(\omega)$ data were fitted to the Havriliak-Nagami expression [25, 26]

$$
\varepsilon^{*}(\omega)=\varepsilon_{\infty}+\frac{\varepsilon_{0}-\varepsilon_{\infty}}{\left[1+(i \omega \tau)^{1-\alpha}\right]^{\beta}},
$$

where $\varepsilon_{0}$ and $\varepsilon_{\infty}$ is the static and high-frequency permittivity, $\tau$ is the relaxation time, $\omega$ is the angular 


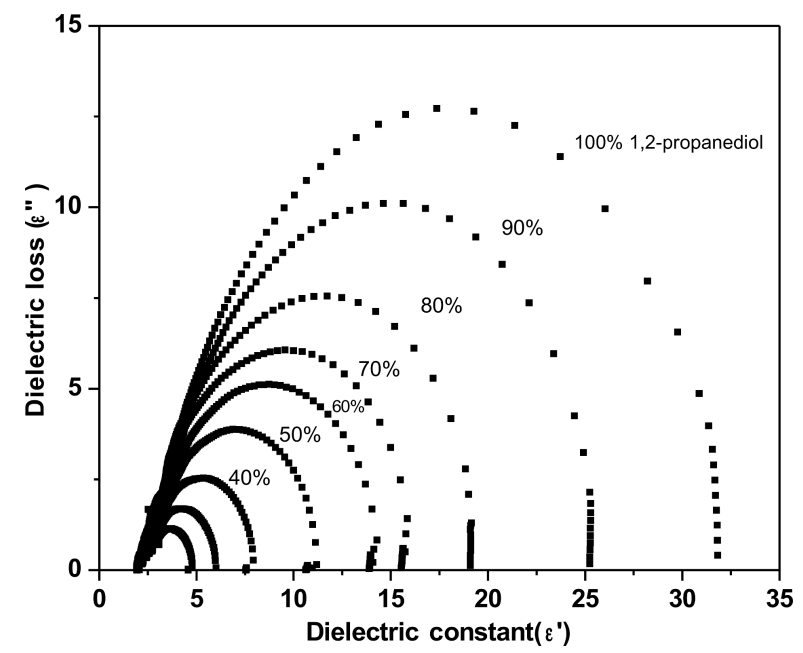

Fig. 3. Cole-Cole plot for 1,2-propanediol-dioxane mixtures at $25^{\circ} \mathrm{C}$.



Fig. 4. Variation of static dielectric constant for 1,2-propanediol with dioxane content at $25^{\circ} \mathrm{C}$.

frequency, and $\alpha$ and $\beta$ are the distribution parameters. From the Cole-Cole plot (Fig. 3) of the mixtures at $25^{\circ} \mathrm{C}$, the dielectric relaxation represented by the Debye relaxation $(\alpha=0, \beta=1)$ can be seen. However, a slight deviation from the Debye behaviour was found in same solutions. The values of the errors are estimated by assuming $2 \%$ errors in the values of dielectric permittivity and loss from the goodness of fit of the data with Eq. (1). Change in static dielectric constant with volume fraction of alcohol concentration for alcoholdioxane mixture is shown in Fig. 4. Relaxation time decreases with alcohol concentration in alcohol-dioxane mixtures, which is shown in Fig. 5.

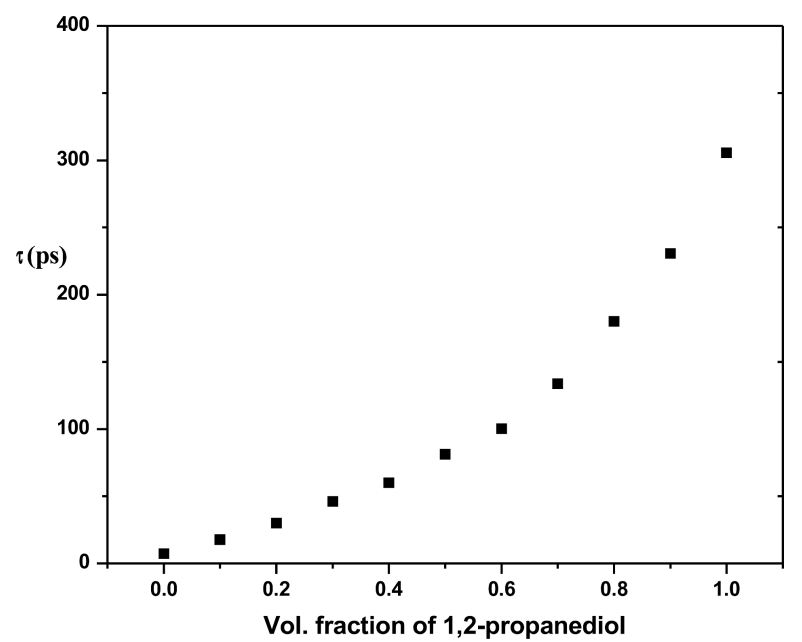

Fig. 5. Variation of relaxation time for 1,2-propanediol with dioxane content at $25^{\circ} \mathrm{C}$.

The contribution of hydrogen bonds to the dielectric properties of the mixture is also studied in terms of the excess dielectric permittivity $\varepsilon_{0}^{\mathrm{E}}$ and the excess inverse relaxation time $(1 / \tau)^{\mathrm{E}}$. These are determined using the following equations for the 1,2-propanedioldioxane solutions [25, 27]:

$$
\begin{aligned}
\varepsilon_{0}^{\mathrm{E}} & =\left[\left(\varepsilon_{0}\right)_{\mathrm{D}} X_{\mathrm{D}}+\left(\varepsilon_{0}\right)_{\mathrm{A}}\left(1-X_{\mathrm{D}}\right)\right], \\
\left(\frac{1}{\tau}\right)^{\mathrm{E}} & =\left(\frac{1}{\tau}\right)_{\mathrm{m}}-\left[\left(\frac{1}{\tau}\right)_{\mathrm{D}} X_{\mathrm{D}}+\left(\frac{1}{\tau}\right)_{\mathrm{A}}\left(1-X_{\mathrm{D}}\right)\right],
\end{aligned}
$$

where $\mathrm{m}, \mathrm{D}$, and $\mathrm{A}$ correspond to mixture, dioxane, and 1,2-propanediol respectively, and $X_{\mathrm{D}}$ is the volume fraction of dioxane in 1,2-propanediol. The variations of excess dielectric constant and excess inverse relaxation time with volume fraction of dioxane in alcohol are shown in Figs. 6 and 7, respectively. The excess dielectric constant and inverse of relaxation time for alcohol-dioxane mixtures show negative behaviour. The observed negative values indicate strong heteromolecular interactions in liquid mixtures and this can be attributed to hydrogen bonding interactions between alcohol and dioxane molecules.

To understand the number of hydrogen bonds per alcohol and dioxane molecules, we apply the KirkwoodFrohlich theory to determine the dielectric constant for alcohol-dioxane mixtures by using Kirkwood-Frohlich equation as follows [27-29]:

$$
\frac{\left(\varepsilon_{0 i}-\varepsilon_{\infty i}\right)\left(2 \varepsilon_{0 i}+\varepsilon_{\infty i}\right)}{9 \varepsilon_{0 i}}=\frac{4 \pi N \mu_{i}^{2} \rho_{i}}{9 k T M_{i}} g_{i}
$$

where $i=1,2$ represent 1,2-propanediol and dioxane respectively; $\mu_{i}$ is a corresponding dipole moment in gas phase, $\rho_{i}$ is the density, $k$ is the Boltzmann constant, $T$ is the temperature, $\varepsilon_{0 i}$ and $\varepsilon_{\infty i}$ are the static 


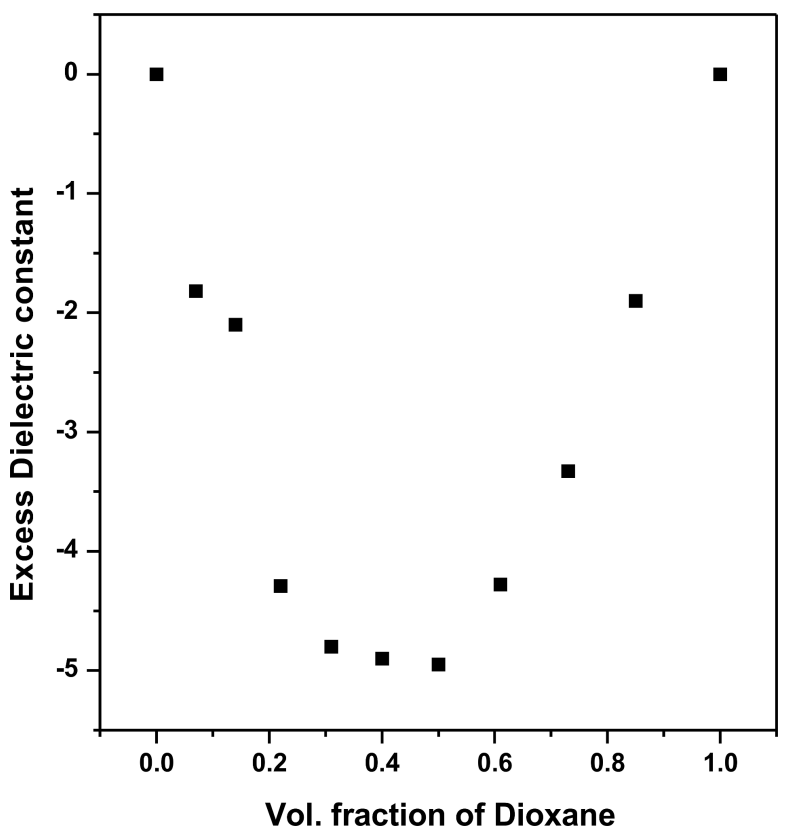

Fig. 6. Variation of excess dielectric constant for 1,2-propanediol with dioxane content at $25^{\circ} \mathrm{C}$.

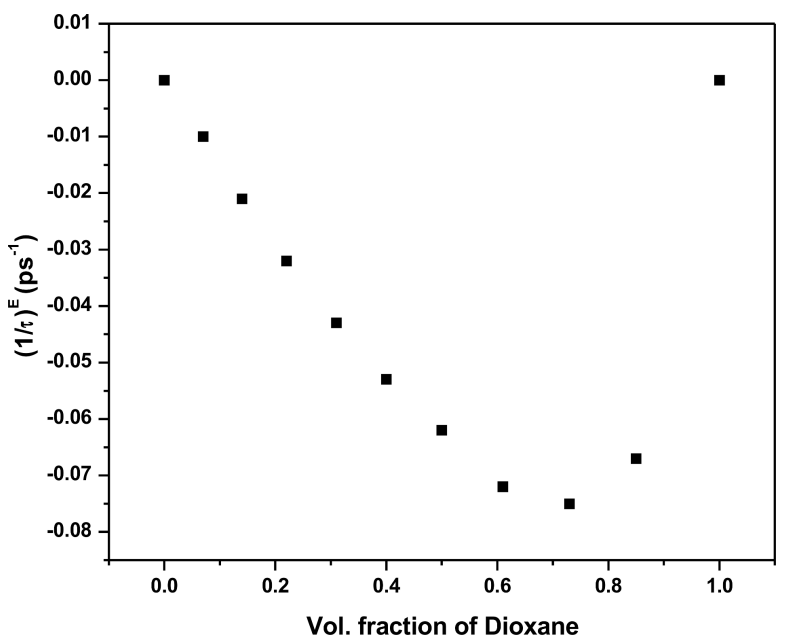

Fig. 7. Variation of inverse excess relaxation time for 1,2-propanediol with dioxane content at $25^{\circ} \mathrm{C}$.

dielectric constant and dielectric constant at high frequency; $g_{i}$ is the Kirkwood correlation factor for the $i$ th liquid system.

We have assumed that the mixture can be represented by one correlation factor $g^{\text {eff }}$ as follows:

$$
\begin{aligned}
& \frac{\left(\varepsilon_{0 i}-\varepsilon_{\infty i}\right)\left(2 \varepsilon_{0 i}+\varepsilon_{\infty i}\right)}{9 \varepsilon_{0 i}}= \\
& \frac{4 \pi N}{9 k T}\left[\frac{\mu_{\mathrm{A}}^{2} \rho_{\mathrm{A}}}{M_{\mathrm{A}}} X_{\mathrm{A}}+\frac{\mu_{\mathrm{D}}^{2} \rho_{\mathrm{D}}}{M_{\mathrm{D}}}\left(1-X_{\mathrm{A}}\right)\right] g^{\text {eff }},
\end{aligned}
$$

where $\mathrm{A}$ and $\mathrm{D}$ stand for alcohol and dioxane, $X_{\mathrm{A}}$ is the volume fraction of 1,2-propanediol. The value of $g^{\text {eff }}>$
1 indicates average parallel orientation of electric dipole in a molecule. It can be seen that as 1,2-propanediol is added in dioxane at regular steps in the mixture the value of $g^{\text {eff }}$ increases.

We also assume that correlation factors of 1,2-propanediol and dioxane molecules are affected by the same amount $g_{\mathrm{f}}$ in the mixture [28]. The KirkwoodFrohlich equation for the mixture can be written as

$$
\begin{aligned}
& \frac{\left(\varepsilon_{0 i}-\varepsilon_{\infty i}\right)\left(2 \varepsilon_{0 i}+\varepsilon_{\infty i}\right)}{9 \varepsilon_{0 i}}= \\
& \frac{4 \pi N}{9 k T}\left[\frac{g_{\mathrm{A}} \mu_{\mathrm{A}}^{2} \rho_{\mathrm{A}}}{M_{\mathrm{A}}} X_{\mathrm{A}}+\frac{g_{\mathrm{D}} \mu_{\mathrm{D}}^{2} \rho_{\mathrm{D}}}{M_{\mathrm{D}}}\left(1-X_{\mathrm{A}}\right)\right] g_{\mathrm{f}} .
\end{aligned}
$$

The Kirkwood correlation factors $g_{1}, g_{2}$ for individual species are modified by assuming for 1,2-propanedioldioxane mixture that two kinds of intermolecular hydrogen bonds exist. One is the hydrogen bond between the 1,2-propanediol-1,2-propanediol molecules; another is the hydrogen bond between the 1,2-propanediol-dioxane molecules. These new correlations ( $g_{1}$ and $g_{2}$ ) are described by the relation as follows [29]:

$$
\begin{aligned}
& g_{1}=1+Z_{11} \cos \varphi_{11}+Z_{12} \cos \varphi_{12} \frac{\mu_{2}}{\mu_{1}}, \\
& g_{2}=1+Z_{21} \cos \varphi_{21} \frac{\mu_{1}}{\mu_{2}},
\end{aligned}
$$

where $Z_{11}=2\left\langle n_{\mathrm{HB}}^{11}\right\rangle, Z_{12}=2\left\langle n_{\mathrm{HB}}^{12}\right\rangle$, and $Z_{21}=$ $2\left\langle n_{\mathrm{HB}}^{21}\right\rangle X_{\mathrm{A}} /\left(1-X_{\mathrm{A}}\right)$ are the average number of particles forming the hydrogen bond with 1,2-propanediol1,2-propanediol, 1,2-propanediol-dioxane, and dioxane-1,2-propanediol pairs, respectively. $\varphi_{11}$ and $\varphi_{21}$ are the angles between the neighbouring dipoles of 1,2-propanediol and dioxane molecules. The values of $g^{\text {eff }}, g_{\mathrm{f}}, g_{1}$, and $g_{2}$ for 1,2-propanediol-dioxane mixture are reported in Table 1. The values of $g_{1}$ and $g_{2}$ depend on the concentration of dioxane in 1,2-propanedioldioxane mixtures.

The average numbers of hydrogen bonds $\left\langle n_{\mathrm{HB}}^{11}\right\rangle$ and $\left\langle n_{\mathrm{HB}}^{12}\right\rangle$ per 1,2-propanediol molecule for $1 i$-pairs $(i=$ 1,2 ) have been determined according to the following relation [29]:

$$
\left\langle n_{\mathrm{HB}}^{1 i}\right\rangle=\frac{n_{1 i} \omega_{1 i}}{n_{1}},
$$

where $\omega_{1 i}=\left[1+\alpha^{1 i} \mathrm{e}^{-\beta E^{1 i}}\right]^{-1}$ is the probability of bond formation between 1,2-propanediol and dioxane. $n_{1}$ is the number density of dioxane molecules. The value of $\beta$ is $1 / k T$ and $\alpha^{1 i}$ is the ratio of the two sub-volumes of the phase space, related to the nonhydrogen-bonded and hydrogen-bonded pairs. These 
Table 1. Kirkwood correlation factors for 1,2-propanediol-dioxane mixtures.

\begin{tabular}{ccccc}
\hline \multirow{2}{*}{$\begin{array}{c}\text { Volume } \\
\text { fraction of }\end{array}$} & \multicolumn{3}{c}{ Kirkwood correlation factor } \\
\cline { 2 - 5 } 1,2-propanediol $X_{\mathrm{A}}$ & $g^{\text {eff }}$ & $g_{\mathrm{f}}$ & $g_{1}$ & $g_{2}$ \\
\hline 0 & 0.68 & 1.00 & & 1.00 \\
0.1 & 1.15 & 1.11 & 1.25 & 1.22 \\
0.2 & 1.33 & 1.07 & 1.29 & 1.47 \\
0.3 & 1.49 & 1.04 & 1.33 & 1.78 \\
0.4 & 1.61 & 1.03 & 1.37 & 2.15 \\
0.5 & 1.80 & 1.02 & 1.60 & 2.23 \\
0.6 & 1.91 & 1.01 & 1.73 & 2.41 \\
0.74 & 2.04 & 1.01 & 1.83 & 2.69 \\
0.8 & 2.32 & 1.00 & 1.94 & 2.98 \\
0.9 & 2.33 & 1.00 & 2.05 & 3.30 \\
1.0 & 2.48 & 1.00 & 2.16 & \\
\hline
\end{tabular}

hydrogen-bonded pairs have only two energy levels, $E_{11}$ and $E_{12}$, for 1,2-propanediol-1,2-propanediol and 1,2-propanediol-dioxane pair formed bonds, respectively. The values of $\left\langle n_{\mathrm{HB}}^{11}\right\rangle$ and $\left\langle n_{\mathrm{HB}}^{12}\right\rangle$ depend on the number of densities of hydrogen bonding pairs between 1,2-propanediol-dioxane, $n_{12}$, and those between 1,2-propanediol-1,2-propanediol molecule, i. e. $n_{11}=2 n_{1}-n_{12}$. This can be calculated when 1,2-propanediol-1,2-propanediol (11-pair) and 1,2-propanediol-dioxane (12-pair) are formed [29]. Figure 8 shows plot of the average number of hydrogen bonds between 1,2-propanediol-1,2-propanediol molecules (11-pairs) and 1,2-propanediol-dioxane (12-pairs) against mole fraction of 1,2-propanediol. The different parameters required in the Luzar model [29] are dipole moments, polarizabilities, possible number of hydrogen bonds, and angles between dipoles $\cos \varphi_{11}$ and $\cos \varphi_{12}$ for the 1,2-propanediol and dioxane. The best possible values of molecular parameters in our analysis for which static dielectric constant values are in reasonable agreement with the experimental values are given in Table 2. We found that our experimental data can be explained by the theory, provided the values of dipole moments of 1,2-propanediol and dioxane are larger than the corresponding values of dipole moments in the gas phase.

The static permittivity of mixture with volume fraction of solute is given by Bruggeman mixture formula [30]

$$
f_{\mathrm{B}}=\frac{\varepsilon_{0 \mathrm{~m}}-\varepsilon_{02}}{\varepsilon_{01}-\varepsilon_{02}}\left(\frac{\varepsilon_{01}}{\varepsilon_{0 \mathrm{~m}}}\right)^{1 / 3},
$$

where $f_{\mathrm{B}}$ is the Bruggeman dielectric factor. The $\varepsilon_{0 \mathrm{~m}}$, $\varepsilon_{01}$, and $\varepsilon_{02}$ are the static dielectric constant corresponding to mixture, 1,2-propanediol, and dioxane respectively; $X_{\mathrm{A}}$ is the volume fraction of propanediol.

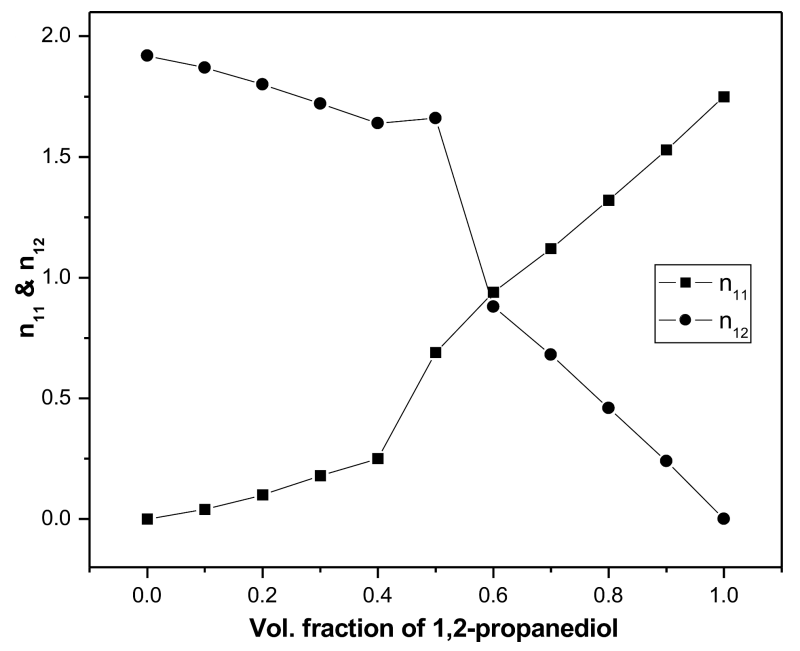

Fig. 8. Plot of average number of hydrogen bonds between 1,2-propanediol-1,2-propanediol molecules (11-pair) and 1,2-propanediol-dioxane (12-pair).

Table 2. Molecular parameters used in computation of the static dielectric constants.

\begin{tabular}{lcc}
\hline Molecular parameters & 1,2-propanediol & 1,4-dioxane \\
\hline Dipole moment $\left(\mu_{1}, \mu_{2}\right)$ & $2.65 \mathrm{D}$ & $0.97 \mathrm{D}$ \\
Polarizabilty $\left(\alpha_{1}, \alpha_{2}\right), \mathrm{A}^{03}$ & 4.94 & 2.79 \\
$\begin{array}{l}\text { Bonding energy } \\
\left(E_{11}, E_{12}\right), \mathrm{kJ} / \mathrm{mol}\end{array}$ & -13.98 & -16.25 \\
Molecular weight, $\mathrm{g} / \mathrm{mol}$ & 76.11 & 88.11 \\
Density, $\mathrm{g} / \mathrm{cm}^{3}$ & 1.0326 & 1.028 \\
Enthalpy $\left(\alpha_{11}, \alpha_{12}\right), \mathrm{kJ} / \mathrm{mol}$ & 40 & 28
\end{tabular}

11 for 1,2-propanediol pair, 12 for 1,2-propanediol-dioxane pair

From the above equation, a linear relation is expected from a plot of $f_{\mathrm{B}}$ versus $X_{\mathrm{A}}$. It can be seen from Fig. 9 that $f_{\mathrm{B}}$ is not a linear function of 1,2-propanediol volume fraction as predicted by Bruggeman equation. The Bruggeman equation may be modified for binary liquid [31] as follows:

$$
\begin{aligned}
f_{\mathrm{B}} & =\frac{\varepsilon_{0 \mathrm{~m}}-\varepsilon_{02}}{\varepsilon_{01}-\varepsilon_{02}}\left(\frac{\varepsilon_{01}}{\varepsilon_{0 \mathrm{~m}}}\right)^{1 / 3} \\
& =1-\left[a-(a-1) X_{\mathrm{A}}\right] X_{\mathrm{A}} .
\end{aligned}
$$

In this equation, volume fraction $X_{\mathrm{A}}$ is changed by a factor $a-(a-1) X_{\mathrm{A}}$ of the mixture; for $a=1$ it corresponds to Bruggeman equation. The value of $a$ can be determined by least squares fit method and is found to be 1.49 , its deviation from unity indicates the molecular interaction in the mixture. 


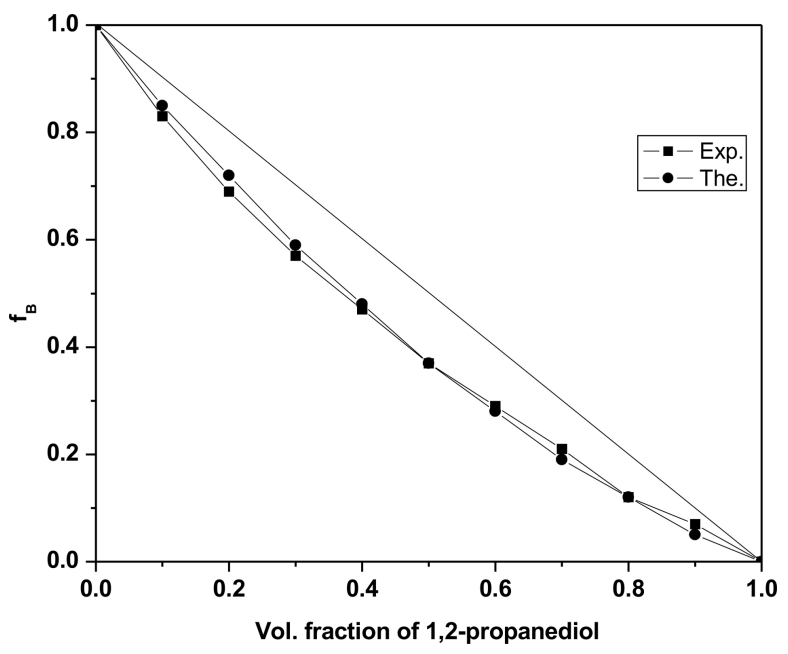

Fig. 9. Variation of Bruggeman dielectric factor with volume fraction of 1,2-propanediol in dioxane at $25^{\circ} \mathrm{C}$.

\section{Conclusions}

The dielectric relaxation parameter for 1,2-propanediol-1,4-dioxane has been determined using TDR method. The dielectric constant for the mixtures can be explained using hydrogen-bonded model by assuming the formation of hydrogen bonds between alcoholalcohol and alcohol-dioxane pairs. The orientation correlations between neighbouring molecules due to hydrogen bonding interaction are determined in terms of Kirkwood factors. A modification in the Bruggeman equation provides a better description of dielectric behaviour in the mixtures.

\section{Acknowledgements}

The financial support from the Department of Science and Technology, New Delhi is gratefully acknowledged (Project No. SR/S2/LOP-25/2007). Author RBT is thankful to Swami Ramanand Teerth Marathwada University, Nanded for providing University Research Fellowship. We thank Prof. S.C. Mehrotra, Dr. M.K. Patil, and Dr. A.S. Choudhari for discussion.

\section{References}

[1] R.J. Sengwa, V. Khatri, and S. Sankhla, J. Mol. Liq. 144(1-2), 89-96 (2009).

[2] S. Sudo, N. Oshiki, N. Shinyashiki, S. Ygihara, A.C. Kumbharkhane, and S.C. Mehrotra, J. Phys. Chem. A 111, 2993-2998 (2007).

[3] R.J. Sengwa, S. Sankhla, and N. Shinyashiki, J. Sol. Chem. 37, 137-153 (2008).
[4] Y. Amo, S. Oshima, and Y. Tominaga, J. Non-Cryst. Solids 353 1916-1919(2007)

[5] S. Sudio, î. Sninyasniki, Y. Kitsuki, and S. Ygihara, J. Phys. Chem. A 106, 458-464 (2002).

[6] T. Sato, A. Chiba, and R. Nozaki, J. Mol. Liq. 101(13), 99-111 (2002).

[7] T. Sato, A. Chiba, and R. Nozaki, J. Mol. Liq. 96-97, 327-339 (2002).

[8] S. Sudo, N. Shinyashiki, and S. Ygihara, J. Mol. Liq. 90, 113-120 (2001).

[9] A.C. Kumbharkhane, M.N. Shinde, S.C. Mehrotra, N. Oshiki, N. Shinyashiki, S. Yagihara, and S. Sudo, J. Phys. Chem. A 113, 10196-10201 (2009).

[10] R.J. Sengwa and S. Sankhla, J. Non-Cryst. Solids 353, 4570-4574 (2007).

[11] S. Chavan, A. Kumbharkhane, and S. Mehrotra, J. Chinese Chem. Soc. 54, 1457-1462 (2007).

[12] G. Guarino, O. Ortona, R. Sartorio, and V. Vitagliano, J. Chem. Eng. Data 30, 366-368 (1985).

[13] B. Garcia, R. Alcade, J.M. Leal, and J.S. Matos, J. Phys. Chem. B 101, 7991-7997 (1997).

[14] F. Corradini, A. Marchetti, M. Tagliazucchi, L. Tassi, and G. Tossi, Aust. J. Chem. 47(6), 1117-1126 (1994).

[15] J. Zielkiewicz, J. Chem. Thermodyn. 35, 1993-2001 (2003).

[16] G. Moumouzias, D.K. Panopoulos, and G. Ritzoulis, J. Chem. Eng. Data 36(1), 20-23 (1991).

[17] G.E. Papanastasiou and I.I. Zlogas, J. Chem. Eng. Data 37, 167-172 (1992).

[18] F. Rived, M. Roses, and E. Bosch, J. Chem. Eng. Data 40(5), 1111-1114 (1995).

[19] J. Nath and S.K. Chaudhary, J. Chem. Eng. Data 37, 387-390 (1992).

[20] P. Scharlin and K. Steinby, J. Chem. Thermodyn. 35(3), 279-300 (2003).

[21] J. Zielkiewicz, J. Chem. Thermodyn. 38, 701-706 (2006).

[22] C.M. Romero and M.S. Paez, J. Chem. Thermodyn. 40, 1645-1653 (2008).

[23] J. Crossely, Can. J. Chem. 56, 352-354 (1978).

[24] F.F. Hanna, Bo Gestblom, and A. Soliman, Phys. Chem. Chem. Phys. 2, 5071-5075 (2000).

[25] A.C. Kumbharkhane, S.M. Puranik, and S.C. Mehrotra, J. Chem. Soc. Faraday Trans. 87, 1569-1573 (1991).

[26] S. Havriliak and S. Negami, J. Polymer Sci. Part C 14, 99 (1966).

[27] A.C. Kumbharkhane, S.M. Puranik, and S.C. Mehrotra, J. Solution Chem. 21(2), 201-212 (1992).

[28] A.C. Kumbharkhane, S.M. Puranik, and S.C. Mehrotra, J. Mol. Liq. 51(3-4), 261-277 (1992).

[29] A. Luzar and J. Stefan, J. Mol. Liq. 46, 221-238 (1990).

[30] D.A.G. Bruggeman, Ann. Phys. (Leipzig) 24, 636-664 (1935).

[31] S.M. Puranik, A.C. Kumbharkhane, and S.C. Mehrotra, J. Mol. Liq. 59(2-3), 173-177 (1994). 


\section{DIHIDROALKOHOLIO IR 1,4-DIOKSANO JUNGINIŲ DIELEKTRINĖS RELAKSACIJOS TYRIMAS LAIKINE REFLEKTOMETRIJA}

M.N. Shinde, R.B. Talware, A.C. Kumbharkhane

Swami Ramanand Teerth Marathwada universitetas, Nandedas, Maharaštra, Indija

\section{Santrauka}

Naudojant laikinę reflektometriją, matuota 1,2-propandiolo ir 1,4-dioksano mišinių kompleksinè dielektrinè skvarba $10 \mathrm{MHz}-$ $20 \mathrm{GHz}$ dažnių srityje, esant skirtingoms mišinių koncentracijoms. Mažiausių kvadratų metodu nustatytos dvinarių mišinių statinès dielektrinès konstantos, relaksacijos trukmès ir Brugemano daugikliai. Dielektrinès mišinių konstantos skaičiuotos pagal Kirk- vudo ir Friolicho teoriją. Ji tinkamai atkartoja 1,2-propandiolo ir 1,4-dioksano mišinių eksperimentines statinès dielektrinės konstantos vertes. Viršijantieji parametrai patvirtina, kad heteromolekulinès vandenilinio ryšio sąveikos 1,2-propandiolo ir dioksano molekuliu mišinyje yra gerokai skirtingos. Mišinių eksperimentiniams dielektriniams duomenims priderintas netiesinio atvejo Brugemano modelis. 